Association. The real question to which Mr. Reynolds's tests point is probably how far theories which rest on the hypothesis that elasticity is perfect can properly be applied to cases where the breaking point has been nearly reached; and this is a question on which more light is very urgently needed, especially with reference to such cases as screw-shafts, where fractures, as a matter of fact, do very commonly occur.

The second paper, by Mr. W. Ford Smith, dealt with twist drills, milling machines, and other methods for the cutting and dressing of metal surfaces, which have been introduced within the last few years; and was almost entirely of a practical character. The third paper, by Mr. John Jameson, was on "Improvements in the Manufacture of Coke," and dealt with a new method, invented by the author, for recovering the gas, gas-tar, and ammoniacal liquor, which are separated from coking coal during the process of carbonisation. As the paper points out, these products are not originally present in the coal. There is, for instance, no ammonia in coal; but there are combinations containing nitrogen and hydrogen, and in almost any process of distillation parts of the evolved nitrogen and hydrogen unite, under very obscure conditions, to form ammonia, which, however, is not stable, but readily decomposes in the presence e.g. of oxygen. Every process of distillation, in fact (but some much more than others), favours the formation of gas on the one hand and of condensable hydrocarbons on the other. With regard to the former, its value in the neighbourhood of coke-ovens is not usually high, and it is a question whether it may not best be burnt in the oven itself, to furnish the heat required in any case for the distilling process ; but the value of tar and ammonia is great, and would probably not fall very low, even if the production were largely increased. At the same time, as a fuel they are not even equal to the same weight of pure carbon. It will be seen, therefore, that there is ample room for a process which will enable us to separate and utilise these by-products, instead of simply using them as fuel, or, which is far worse, discharging them unburnt to poison the air and destroy vegetation. Mr. Jameson's methnd of effecting this end is very simple. He takes an ordinary "beehive" coke-oven, makes it tolerably airtight by letting tar soak into the brickwork, and covers the floor wich an impervious substance, in which are inserted some large bricks or quarls, pierced with holes. Below these is a chamber connected with a pipe, which leads, through any convenient form of condenser, to a small exhausting fan. The oven is now charged and lighted from the top, to which alone air is admitted. The heat of combustion, penetrating downwards, gradually distils the pitch and gases out of the coal, and the fan being set to work, these products, instead of passing upwards to the fire, are sucked downwards through the holes in the floor, and afterwards separated, the tar being left in one condenser, the ammoniacal liquor in another, and the gas either used at once for steam-raising, \&c., or stored in a gas-holder till required.

In the discussion which followed, the advantage of saving the waste products was fully admitted, though some rather startling estimates of the author (who had assumed that $75,000,000 l$. per annum was practically wasted under our present system of coal consumption) were sharply criticised. But by the ironmasters who were present it was strongly laid down that the first duty of a coke-oven was to make good coke-such coke as would give the best results in a blast-furnace ; and that to this duty all consideration of by-products must give way. It was further suggested that pitch was a valuable ingredient in coke, and that this pitch was left in it by the present system, but withdrawn on the new one. This idea, however, seems to be founded on a misapprehension. $\mathrm{Mr}$. Jameson and others were able to state positively that the coke made by his process could not be distinguished in quality from the product of the old beehive oven; that the quantity per ton of coal was the same; and that the by-products, though differing very greatly in quantity according to the character of the coal, method of condensation, \&c., were almost always sufficient to repay, within a few months or even weeks, the $10 l$. or $15 l$. required to adapt an existing oven to the new arrangement. If these results are confirmed by more extended trials in different localities, the process seems likely, as one speaker phrased it, " to take a pretty prominent position among the great inventions of the present day."

\section{CORONERS' SCIENCE IN CHINA}

W HETHER Chinamen are or are not believers in the principle that it is better that nine guilty persons should escape rather than that one innocent person should suffer, they do at all events, by their manner of conducting inquests, leave open a wide door for the escape of murderers. A deeply-rooted repugnance to dissection of the human body and a consequently slight acquaintance with anatumy, coupled with an entire ignorance of the action of poisons, deprive coroners of every means of arriving at decisions except those furnished by outward symptoms and appearances. From early times, however, the importance attaching to human life has been recognised by the custom of holding inquests in cases of sudden death, and various works have been published embodying all the knowledge available on the subject to assist coroners in their duty of investigation. The best-known of these was the Se yuen luh, or "Record of the washing away of wrongs," which was given to the world in the thirteenth century, and which, under the same title, subsequently received the imprimatur of the officers of the Board of Punishments, who, in the exercise of their legislative function, issued it as a manual for coroners. In this work is expounded the whole system of Chinese medical jurisprudence, of which the following is a slight sketch.

One of the first directions given to coroners reminds one of Mrs. Glasse's celebrated dictum, and is to the effect that before issuing a warrant for an inquest they should be quite sure that there really is a corpse. This admonition is no less curious than the reason which makes it necessary. It appears to be not uncommon for unscrupulous swindlers to demand inquests on imaginary corpses for the purpose of extorting money from the wealthy owners of the houses where the bodies are said to be, who, rather than fall into the clutches of the law, generally pay the sum demanded on condition that all proceedings are stayed. But being well assured of the existence of a corpse, the coroner should proceed to the spot well provided with onions, red pepper, salt, white prunes, and vinegar with the lees. If death has just taken place, he should examine the top of the head, back of the ears, throat, and any other vital part where a sharp-pointed instrument may have been inserted. In case of his failing to find any such cause of death, he should interrogate the friends and neighbours, and then proceed to examine any wounds there may be on any other part of the person.

An infallible guide to the date of a wound is found in the colour of the bone affected. If it is a recent one or of a slight nature, the bone will be red, but if old and severe, the bone will be of a dark blue colour. Particular care should, however, be taken to as:ertain that these colours are genuine, and not manufactured to agree with the story told by the relatives. A red tint may be given to the bone by painting it with an ointment of genuine safflover, sapanwood, black plums, and alum, with the addition of boiling vinegar. On the other hand, green alum or nutgalls, mixed with vinegar, impart a dark blue or black hue. These counterfeit colours may, however, be distinguished by their want of brightness. Again, not uncommonly a fictitious wound is made after death by 
burning the spot with lighted strips of bamboo, but such a wound will be level with the surrounding flesh and be soft to the touch. If willow bark has been used for the same purpose, the flesh will be rotten and black, livid all round, and free from hardness. A lighted paper placed inside a cup and applied to the flesh makes a wound which resembles the result of a blow with the fist ; but it will be observed that all round there is a red, scorched mark, that the flesh inside is yellow, and that although it swells, it does not become hard. On the other hand, a genuine wound can be distinguished by the well-defined colours of the surrounding flesh. At the extremity of the wound there should be " a halo-like appearance, like rain seen from a distance, or like fleecy clouds, vague and indistinct."

Murders, it is held, are seldom the result of premeditation, but are in a great majority of cases to be traced to drunken brawls ; and further, coroners should remember that the relatives of a wounded man, unless their ties be of the closest, desire his death that they may extort money from his slayer. It becomes their duty, therefore, on hearing of a fray in which any one has been seriously wounded, to see that the injured man be carefully tended and provided for. If death ensues, a careful examination of the corpse should be made, beginning from the head downwards, and in doing so, should it be suspected that tattoo-marks on his cheeks or elsewhere have been obliterated, such parts should be tapped with a slip of bamboo, which will have the effect of making the marks reappear. Attention should be given to see if the ears have been bitten or torn, whether the nostrils have been wounded, and whether the lips are open or closed. The teeth should be counted, the jaws examined, and the limbs carefully scrutinised down to the finger- and toe-nails. If the body bears marks of corporal chastisement, it should be noted, and any scars there may be, both on the inside and outside of the ankle-bones, may be safely set down to torture. When the mark of a wound which is known to have been inflicted cannot be traced, vinegar with the lees should be poured on the spot, and a transparent piece of oilcloth be held between the sun and part to be observed. On a dull day live charcoal must take the place of the sun. If the result be not satisfactory, spread powdered white prunes, with more vinegar and lees, and examine closely. Should this also prove unsatisfactory, then a cake composed of the flesh of white prunes, red pepper, onions, salt, and lees should be made very hot over a fire and applied to the parts, when the wound will appear.

In the same way, when violence is suspected, but no injury is at first sight apparent, it is directed that vinegar with the lees should be poured on the body, over which the clothes of the deceased saturated again with hot vinegar should be laid, and, covering all, mats spread to keep the steam in. The temperature of the vinegar should be regulated by the season of the year, and in very cold weather, when the vinegar, however hot, is insufficient to relax the rigidity, the corpse should be laid in a hole in the ground, in which a roaring fire has been subdued by copious sprinklings of vinegar. The fumes of steam which will then arise may be expected to accomplish the object. A careful examination should then be made, and if the marks of a wound or wounds are observed on the skin, their size, shape, and position are to be carefully noted, and death attributed to the one on the most vulnerable part. One of the most curiously perverted pieces of coroners' science is contained in the assertion that, if death has arisen from a blow on the lower part of the abdomen, the injury is discoverable by the condition of the roots of either the top or bottom teeth in the case of men, and in that of women by the appearance of the gums.

If the services of the coroner should not be called in until the body is in so advanced a staye of decomposition that the condition of the bones is the only test left him, he should choose a bright day, and having steamed them in the fumes of hot vinegar he should examine them under a red oilcloth umbrella. The blood having soaked into the injured parts, these will at once become visible, and will leave clearly-defined red, dark blue, or black marks. A long-shaped, dark-coloured mark so discovered points to a wound inflicted by a weapon, a round one to a blow of the fist, a large one to a butt of the head, and a small one to a kick. The fact of saturation of blood in the bone is evidence that the wound was inflicted before death. Should there be any doubt as to the identification of the bones, it is only necessary for a child or grandchild of the deceased to cut himself and herself with a knife, so that the blood may drip upon the bones, when, if they be really those of the parent, the blood will soak into them, otherwise it will not. In connection with this test it is curious to find stated the old-world belief that the blood of relations, if dripped into a basin, will mix, and not in the case of others. This test would appear to be often appealed to, since coroners-though it is difficult to see what it has to do with coroners-are warned to see that those interested in proving a relationship do not smear the basin with salt or vinegar, under the influence of either of which any bloods will mix.

Observations have shown, so coroners are told, that a man who has been killed with a knife dies with his mouth and eyes open and his hands clenched. The skin and flesh about the wounds will be shrunken, and in case of a limb having been cut off the bone will be protruding. Where decapitation has taken place, the muscles will have shrunk backwards, the skin will have curled over, and the shoulders will be shrugged up. These appearances will be wanting if the wounds have been made after death has taken place. It is necessary to be particular on these points, we are told, as murderers const intly endeavour to mislead coroners by inflicting wounds after death in such a way as to lend a colour to vampedup stories of suicide. The exact frame of mind in which a man was when committing suicide can be readily discovered by the features of the corpse. If the teeth are firmly set, the eyes slightly open and looking upwards, a fit of violent passion prompted the act ; if the eyes are closed, but not tightly, the mouth slightly open, and the teeth not shut, then it was due to an excess of pent-up rage; if fear of punishment has driven him to it, his eyes and mouth will be placidly closed, "for he looks on death merely as a return home and a happy release from the responsibilities of life." The hands also furnish a test when there is a doubt whether the case of a man whose throat has been cut be one of murder or suicide. The hand with which a suicide commits the deed will remain soft for a time, and will curl up a day or two after death, neither of which symptons will occur when death has been caused by another person.

Strangulation is one of the commonest mean by which persons tired of life "shuffle off this mortal coil," and full directions are given as to the points to be observed when holding inquests on such cases. The exact position of the body, the kind of scar on the neck, the existence or absence of the mark of a knot, the expression of the face, and a thousand other matters are detailed at length, and are contrasted with similar appearances in the case of murders. One curious piece of superstition receives the sanction of the Board of Punishment in connection with suicide by hanging. Beneath the spot where the crime was committed, at the depth of three or more feet below the surface of the soil, there will be found a deposit of charcoal, and by this test, should any doubt exist as to the scene of the suicide, the matter may be settled. The directions given in the case of deaths by drowning are voluminous, and, speaking generally, accurate. The habit of generalising from insufficient data, which is so common with Chinamen, occasionally leads them astray here as elsewhere. It has been reserved for them, for example, 
to discover the law that bodies take a longer time to float in winter and the beginning of spring than in the summer and end of autumn. That a drowned man floats on his face and a woman on her back is mentioned, and it is left to be implied that in case of bodies having been thrown into the water after death this does not hold good. With the same minuteness every possible circumstance connected with death by fire is gone into at length, the presence of traces of ashes in the mouth and nose being described as " a crucial test of death by burning."

The chapters on poison are, as might be expected in the absence of dissection, the most unsatisfactory in the book. Practically very little light is thrown on the distinguishing symptoms arising from the effects of different poisons. The common test applied to most is that of inserting a silver needle washed with a decoction of Gleditschia sinensis, into the mouth of the corpse. If, when after a time this is withdrawn, it should be stained a dark colour, and remain so stained after it has been again washed with the decoction, poison has been the cause of death. Another proof is furnished by the effect which a pellet of rice, after having been some time in the mouth of the corpse, has on poultry who can be induced to swallow it. The commonest poisons are said to be opium, arsenic, and certain noxious essences derived from herbs. But besides these, other things are taken by suicides and given by murderers to cause death. In some of the southern provinces there exists a particular kind of silkworm, known as the Golden Silkworm, which is reared by miscreants to serve either pu. pose as occasion may require. Quicksilver, which is also used with fatal effect, is either swallowed, or, like the "juice of cursed hebenon" which sent Hamlet's father to his account, is poured into the ear. The torture necessarily consequent on this last method of using it must be so excessive that it may safely be assumed that it finds favour only with murderers. Swallowing gold, on the other hand, seems to be the favourite way of seeking death with wealthy suicides. It has been held by some writers that the expression "swallowing gold" is but a metaphorical phrase meaning "swallowing poison," just as when a notable culprit is ordered to strangle himself he is said to have had "a silken cord" sent to him. But the "Coroners" Manual" puts it beyond question that gold is actually swallowed, and it prescribes the remedies which should be adopted to effect a cure. Gold not being a poison, death is the result either of suffocation or laceration of the intestines. When suffocation is imminent, draughts of strained rice-water, we are told, should be given to wash the gold downwards, and when this object has been attained, the flesh of partridges, among other things, should be eaten by the patient to "soften the gold" and thus prevent its doing injury. Silver is also taken in the same way. But though wealthy Chinamen thus find a pleasure in seeking extinction by means of the precious metals, they have never gone the length of pounding diamonds to get rid of either themselves or their enemies after the manner of Indian potentates.

\section{ROBERT K. DOUGLAS}

\section{ZOOLOGY IN $7 A P A N$}

A CORRESPONDENT in Tokio sends us the followA ing:-During the late summer and autumn some good work has been done in the ornithological way. Mr. P. L. Jouy, of the Smithsonian Institution, collected extensively in the region of Mount Fujiyama, at Chiu-senji Lake, near the celebrated shrines of Nikko, and on Tateyama Range, between the borders of the provinces of Shinshiu and Hida. A large number of beautifully prepared skins, with a good deal of information regarding the breeding habits of some of the rarer birds, is the result, which will be recorded in the February number of the Chrysanthemum, a magazine published at Yokohama, appearing in enlarged form with the commencement of this year. An article contributed by Capt. Blakiston in the January number, follows up those of his for September, October, and November, I 882, on ornithological work in Yezo during the past summer; in which is noticeable the occurrence of Locustella certhiola (Pall), and Phyllo. scopus borealis (Blasius) on that island; and the discovery of a new species of Motacilla (probably described by Seebohm in the Ibis for January, $188_{3}$ ), allied to $M$. ocularis (Swinhoe) and M. amurensis (Seebohm), which has hitherto somehow been mixed up with $M$. lugens of the "Fauna Japonica," which latter is now found to be -to quote Capt. Blakiston's words (Chrysanthemum, January, I 883, p. 31)--"a species unique in its genus, having in the adult state the same appearance winter and summer, and in which the young pass at once before their first winter into the adult dress."

Messrs. Owston, Snow, and Co.'s otter hunters at the Kuril Islands have also during the past season added some new localities for Japan birds. The specimens are in the hands of Capt. Blakiston, and will be duly mentioned in the following number of the Chrysanthemum, as additional notes to the "Birds of Japan," I rans. As. Soc. fapan, vol. $x$. part I (noticed in NATURE, vol. xxvi. p. 362)

In the way of mammalia late investigation points to the distinctness of Yezo from Japan proper. The Rev. Père Heude, who is now engaged upon a revision of the Cervida of Eastern Asia, has come to the conclusion that the common deer of Yezo is not $C$. sika of the "Fauna Japonica," but C. manchuricus-minor, or an undescribed species. Two parts are already publishedvery creditably got up at the Mission Press at Sikawei, near Shanghai-cf. "Mémoires concernant l'Histoire Naturelle de l'Empire Chinois," others being promised to follow.

\section{NOTES}

THE following is the list of fifteen candidates recommended for election by the Council of the Royal Society :-Surgeon. Major James Edward Tierney Aitchison, M. D., James Crichton Browne, M.D., LL.D., Surgeon-Major-George Edu ard Dobson, M. B., James Matth $=$ ws Duncan, M.D., Prof. George Francis Fitzgerald, M.A., Walter Flight, D.Sc., Rev. Percival Frost, M.A., David Gill, LL.D., Charles Edward Groves, F.C.S., Howard Grubb, F.R.A.S., John Newport Langley, M.A., Arnold William Reinold, M.A., Roland Trimen, F.L.S., F.Z.S., John Venn, M.A., John James Walker, M.A.

THE loss sustained by mathematical science in the premature death of Henry Stephen Smith is still fresh in the minds of our readers. They will find their best consolation in the fact that his successor in Oxford may possibly be Prof. Sylvester. Such an opportunity of recovering for England the services of one of her two greatest mathematicians is not likely to recur, and will, we doubt not, be eagerly turned to advantage. It has been a humiliating thought to many to whom the highest interest of science is dearer than the prosperity of mere mediocrity that, of the two greatest mathematicians that iEngland has produced in the nineteenth century, one has altogether and another almost been obliged to seek for refuge in a foreign land.

UNIVERSAL regret wi'l be felt at the sad intelligence which has just reached England by telegram, from Madeira, of the un. timely death of Mr. William Alexander Forbes, B. A., Fellow of St. John's College, Cambridge, and Prosector to the Zoological Society of London. Mr. Forbes left England in July last, along with Mr. McIntosh and Mr. Ashbury, upon what was expected to be a three or four months' expedition in a steam. yacht up the river Niger. He died of dysentery at Shonga on January I4, aged 28 . 